\title{
UNTANGLING THE DIGITAL EXHAUSTION
}

\section{Beatriz Santos Dias*}

\begin{abstract}
Summary: 1 . Introduction; 2. Conceptualizing the Exhaustion; 3. New Digital: Old challenges; 4. Challenging the Meaning of Copyright with Virtual Content; 5. Solving the Panacea: A Place for Digital Exhaustion; 6. Technological Protection Measures: The regulation's Allied; 7. Conclusion.
\end{abstract}

\begin{abstract}
Through this essay, we will focus on the defensibility of a digital exhaustion principle in both legal and practical dimensions regarding the workability and acceptance under the new digital paradigm.

The principle of exhaustion is expressively recognized at both the international and European level as a limit to the right of the original owner's right of distribution. Attending to the meaning of frontiers in the digital ecosystem, hence the underlying idea behind the principle of exhaustion is to facilitate the functioning of the internal market by eliminating the barriers to the free movement of goods within the European Union.

To this end, we will analyse the applicability of the principle of exhaustion to the online dissemination of digital copyrightable content in the Digital Single Market attending to the existing statutory framework within the EU along with the recent case law. While bearing in mind the existing challenges in the field of copyright law with the massive digitalization, the unprecedented number of copies available online facilitating piracy and dissemination at an almost near-zero cost. We will undertake a solution based on the synergy of means for policy in light of the $21^{\mathrm{st}}$ century challenges and technologies available. Therefore, we propose a model that combines both legal and technological tools.
\end{abstract}

KEYwORDs: Principle of Exhaustion, Digital Exhaustion, Distribution Right, Digital work, Digital Copy, Virtual Content, Digital Transfers, Regulation, Digital Single Market, E-books, Intangibility, Blockchain, Forward and Delete

RESUMO: Ao longo do presente artigo, procederemos a uma análise sobre a aplicabilidade do princípio de exaustão em ambiente digital, e averiguaremos em que medida seria viável no atual panorama jurídico e tecnológico europeu. O princípio

* Mestranda em Direito e Tecnologia na Nova School of Law e Licenciada em Direito pela Faculdade de Direito da Universidade de Lisboa. 
de exaustão é expressamente reconhecido, tanto a nível internacional como europeu, enquanto limite do direito de distribuição. Contudo, tendo presentes a ubiquidade das fronteiras no ecossistema digital e as dificuldades que acarreta no domínio dos Direitos de Autor, consideramos que a aceitação de um princípio da exaustão digital é crucial para fomentar e aprofundar o objetivo do Mercado Único Digital.

Palavras-Chave: Princípio da Exaustão, Exaustão Digital, Direito de Distribuição, Obra Digital, Cópia Digital, Transferências Digitais, Regulação, Mercado Único Digital, Livros Digitais, Intangíveis, Blockchain 


\section{INTRODUCTION}

As the ongoing revolution in information technologies spreads in ever more areas of life, the advances in digital technology shape the world around us in an unprecedented way, setting new challenges to fundamental rights and raising new questions regarding the adequacy of the existing legal framework to the changing reality. In an era where Amazon sells more e-books than hardcovers and paperbacks combined ${ }^{1}$, we must face the new 4.0 context where interactive on demand transmission and digitalization rise new quests for copyright law.

Through this essay, we will focus on the defensibility of a digital exhaustion principle in both legal and practical dimensions under the new digital paradigm, whereby the traditional dichotomy between tangible and intangible mediums of expression is no longer clear. As regards the expanding networking environment and e-commerce, which greatly increases the copying and dissemination, in a place where one might struggle to differentiate the copy from the original. Now, more than ever, the substantive copyright law and the existing legal system in the internet age is in the line.

Whereas we will proceed by analysing the extent of the exhaustion principle to acts of online dissemination in digital copyrightable content throughout our Digital Single Market (hereinafter 'DSM'), attending to the existing statutory framework within the European Union (hereinafter 'EU'). In addition, the recent verdicts held by the CJUE have shaped the different notions of digital exhaustion worldwide.

Undoubtedly, one must consider the meaning of frontiers and the importance of the exhaustion for the functioning of the internal market, eliminating barriers to the free movement of goods within the EU, while ensuring the balance between copyright and the protection of competition, innovation and fundamental freedoms. Despite the existing challenges, as we endeavour a comprehensive and adaptive approach towards the acceptability of digital exhaustion. Considering the existing legal framework entails a solution based

1 "Amazon Says Now Selling More E-Books Than Print Books", Forbes Magazine, last accessed in 21 December, 2020) https://www.forbes.com/sites/ericsavitz/2011/05/19/amazon-says-now-sellingmore-e-books-than-print-books/ 
on the synergy of means for policy in light of the $21^{\text {st }}$ century challenges and technologies available, we propose a model that combines both legal and technological tools.

\section{Conceptualizing The Exhaustion}

Under copyright law, the principle of exhaustion states that, once the primary rightsholder has placed a copyrightable work in the market, the right to control the subsequent distribution of that work is exhausted. In fact, the principle of exhaustion is one of the cornerstones in Intellectual Property (hereinafter 'IP'), hence generally referred to as original rightsholder of the intellectual creation that only controls the distribution until the first sale, therefore defining the scope of the distribution right granted to the original rightsholders.

Originally, the idea was to ensure a fair balance between the user's property rights over the material support and the author's exclusive rights over the intellectual creation, consequently coordinating the protection with the need to ensure access and availability to the creations. Hence, the exhaustion necessarily implies a trade-off between the interests of the rightsholder in controlling the distribution rights granted by copyright law in line with essential rights of free movement ${ }^{2}$, as it implies two natural lengths: the copyright dimension and internal market and consequently comprising two limitations as well: to the right of distribution after the first sale and to the right of opposition of the free movement of goods in the EU.

Within the European regulatory framework, the principle of exhaustion is provided under Article 4(2) of the Information Society Directive ${ }^{3}$ (hereinafter 'InfoSoc.') for works, Article 4(2) of the Software Directive ${ }^{4}$ for computer

\footnotetext{
2 Andreas Wiebe, "The Principle of Exhaustion in European Copyright Law and the Distinction between Digital Goods and Digital Services", in GRUR meets Brussels, Brussels, 2008.

3 Directive 2001/29/EC of the European Parliament and of the Council of 22 May 2001 on the harmonisation of certain aspects of copyright and related rights in the information society.

4 Directive 2009/24/EC of the European Parliament and of the Council of 23 April 2009 on the legal protection of computer programs.
} 
programs, and in 9(2) of the Database Directive ${ }^{5}$ for databases. The underlying idea behind the exhaustion lays in the sense of territoriality in Copyright, which may conflict with Articles 34 and 35 of the TFUE on the prohibition of restrictions in the free movement of tangible goods throughout the EU. Thus, Article 36 partially recognizes the principle of exhaustion as a limitation to the right of artists to follow their work after the first sale.

To apply the principle of exhaustion, certain legal requirements must be fulfilled: (1) a property transfer, which depends upon an act of disposal; (2) lawfulness (of the act of disposal) and (3) the tangibility, since, as a rule, the principle of exhaustion is only applicable in materialized mediums of expression.

Considering such requirements, authors argue that both the transference and the tangibility express the legislator's intention in limiting the applicability of the exhaustion to immaterial supports of the intellectual creations ${ }^{6}$. Others ${ }^{7}$ outline the similarities among tangible and intangible copies and that no substantial distinctions appear to explain the different treatment between material and immaterial mediums of expression, therefore advocating for the digital exhaustion. Differently ${ }^{8}$, some authors consider that this issue is not sufficiently problematic to lead to any real changes in the exhaustion doctrine.

In line with the gradual erosion of the dichotomy between tangible and intangible, the application of exhaustion was limited by the fact that the use of any tangible copy is bound to the physical location of that piece of work, unlike any other use offered as a service. Additionally, the lack of deterioration in the digital environment leads to a higher risk in terms of piracy, ultimately impacting the primary market of sale and limiting the rightsholder's afterward exploitation.

5 Directive 96/9/EC of the European Parliament and of the Council of 11 March 1996 on the legal protection of databases.

6 Alberto Sá e Mello, Manual dos Direitos de Autor e Direitos Conexos (Almedina, Coimbra, 2019), 196.

7 Oliveira Ascensão, Direitos de Autor e Sociedade de Informação, (Coimbra, Coimbra Editora, 2012).

8 Alexandre Dias Pereira, "Arte, Tecnologia e Propriedade Intelectual", Revista da Ordem dos Advogados, A.62, Vol.II, 2002. Available in https://portal.oa.pt/publicacoes/revista/ano-2002/ ano-62-vol-ii-abr-2002/artigos-doutrinais/alexandre-dias-pereira-arte-tecnologia-e-propriedadeintelectual/ (accessed in 20 December2020) 
In sum, the exhaustion theory implies that the original rightsholder must accept any further profitable transactions regarding its work once all the aforementioned requirements are fulfilled.

\section{New Digital: Old challenges}

The advent of digital technology and the modern means of communication has profoundly modified the way people interact and transact between each other. Now, legislators and rightsholders face significant challenges due to the advances in the technological fields and the expanding digital environment.

To start with, the quality of the copy does not deteriorate over time and use which consequently leads to a higher risk of piracy, ultimately impacting the primary market of sale. In light of this context, courts have rejected the construction of a digital exhaustion, hence the mass reproduction phenomenon in a world without scarcity along with the banalized digital piracy and the lack of deterioration with use, which stimulates the advantages of second-hand markets.

In fact, one of the major discussions regarding the feasibility of the digital exhaustion is the meaning and adequacy of the concepts of communication and distribution within the virtual environment. Arguing that the intangibility of the copy commercialized through licencing does not formerly transmit the ownership, triggering the qualification as a service leading to a definition of the transfer as a "communication to the public" instead of distribution.

Secondly, concerning copyright limitations and exceptions, the digital technologies greatly reduce costs in copying, distributing and transforming content leading to a much higher degree of availability of more copyrighted content, but also an easier access and distribution of pirated content. In light of this, policy makers have taken the view that consumers should have the flexibility to make reasonable uses of legitimate acquisition of copyrighted content in the digital age.

Moreover, the volume and velocity in the digital sales of counterfeits and pirated copies are of enormous magnitude and tackling all of them would be a Herculean task, as the level of deployment highly increases in such markets, 
whereby the current level of trade liberalization and e-commerce greatly facilitates global digital exhaustion. Around the world is emerging a new calling for new global solutions to meet the challenges of copyright law in an ever more connected world.

This plethora of opportunities for unauthorized and undetectable accesses to intellectual creations, in intangible form, outlines the need to reconsider the traditional theorization of exhaustion towards an e-exhaustion.

\section{Challenging the Meaning of Copyright ability with Virtual Content}

The content digitisation movement has brought forward some inherent difficulties in the conceptualization of copyright law in the digital society, which poses a variety of challenges to our shifting understanding of property and intellectual property in the digital context. Additionally, the hardships raised in the ownership and attribution of copyright are in line with the concurrent dissipation of the concept of property in a time where copyright is no longer focused upon an individualistic perspective, but in a broad and flexible sense.

Nevertheless, with the banalization of creative content and high level of accessibility and diffusion, one must ask what is the true meaning of copyright in an ever more digitalized society that has led to preludes of a much announced death of copyright.

With time, more digital creative content enters and challenges ever more creative sectors, thus meaning that virtual content is incorporated in the intangible medium of expression. Whereby emerging technologies continue to raise new questions for copyright, particularly with a copyright system built around a law with more than forty years old. And in a time where trade is mainly in digital format, with goods such as e-books, software, music, and other digital items, exposing the flaws in the nature of copyright law ${ }^{9}$,

9 P. Sean Morris, Beyond Trade: Global Digital Exhaustion in International Economic Regulation (May 1, 2013). 36 Campbell Law Review 107 (2014), Helsinki Legal Studies Research Paper No. 31. 
in light of which authors ${ }^{10}$ have called out for the admissibility of a new tertium genus introduced by the digital content and that has hampered the distinction between communication and distribution. For instance, an ultimately example of the sense of the property loss over digital goods was the remote erasure of Orwell's e-books from the kindle's owners by Amazon in $2009^{11}$.

Having in mind the aforementioned challenges, the principle of exhaustion as a posing limit to the distribution right was developed before the internet era. For that reason, the expressed primary and sole application to tangible objects is not surprising. Nevertheless, the distribution of digital files has been rapidly increasing in recent years, now surpassing the threat of physical predominance. Therefore, we must be legally bound with such practical evolutions through an active interpretation of the existing legal framework.

Finally, when considering electronic transferred files, it implies that numerous copies (temporary or not) of the same file are created, leading authors to advocate for a new copy theory ${ }^{12}$ according to which every new copy of file limits the legal disposal of the file, since it is a new one that is being transferred and not the original. In the end only one replica of the file would remain.

\section{Solving the Panacea: A Place for Digital Exhaustion}

For starters, the term 'digital exhaustion' was first used by Aaron Perzanowski and Jason Schultz in a paper discussing the application of the principle of exhaustion in the digital environment ${ }^{13}$. The main quests arising in 10 Alexandre Dias Pereira, Arte, Tecnologia e Propriedade Intelectual, (accessed in 23 December 2020).

11 With an ironic twist since one of the books was Orwell's classic dystopian novel 1984 "ironically like Big Brother, Amazon is monitoring our Kindle content" in Bobbie Johnson, "Amazon Kindle users surprised by 'Big Brother' move", The Guardian, https://www.theguardian.com/technology/2009/ jul/17/amazon-kindle-1984

12 Péter Mezei, "The Theory of Functional Equivalence and Digital Exhaustion - An Almost Concurring Opinion to the UsedSoft v. Oracle Decision", Lege et Fide: Ünnepi tanulmányok Szabó Imre 65. születésnapjára, A Pólay Elemér Alapitvány Könyvtára, Vol. 65.(September, 2016): 387-400., Available in https://papers.ssrn.com/sol3/papers.cfm?abstract_id=2496876

13 Aaron Perzanowski and Jason Schultz, 'Digital Exhaustion', UCLA Law Review, Vol. 58, Wayne State University Law School Research Paper No. 10-10, UC Berkeley Public Law Research Paper No. 1669562. 
the theoretical proposal of exhaustion to digital media concern the online transmission as an act of distribution and the similarity between licenses and sales and the consumer's ownership under the digital media.

As regards to applicability of the e-exhaustion, this possibility was primarily considered in the CJUE leading case law Usersoft ${ }^{14}$. Which concerned the re-sell of second hand software and, although one of the most highly contested decisions, it changed the traditional conception of exhaustion. In light of this path, scholars have been advocating for the acceptance of a new functional equivalence ${ }^{15}$ between licenses and traditional sales. However, as we perceive it, the winning argumentation of the court, based on the lex specialis argument (regarding the applicability of the Software Directive to this particular case), wich does not sufficiently bounds with the particularities of this case.

\section{a) Looking into CJUE case law: Software VS e-books}

More recently, the CJUE has ruled $^{16}$ the inapplicability of the digital exhaustion under the Information Society Directive when considering the re-sale of second hand e-books. In this case, the Tom Kabinet's platform offered used e-books to its subscribers, thus all the files were watermarked and then made available via download. The CJUE ruled that the download for permanent use constituted a 'communication to the public' within the meaning of Article 3(1) Info.Soc. (not subject to the exhaustion doctrine) instead of an act of distribution (Article 4(1)) in accordance with a line of reasoning based on a teleological approach.

14 Case C-128/11- UsedSoft GmbH v Oracle International Corp. In which, according to the CJUE, a customer downloading a copy from the Internet expects to have acquired ownership in that copy. This expectation needs to be protected for the sake of the functioning of the EU's internal market, irrespective of conflicting contractual terms (such as Oracle's), stipulating that the download and the use of software are two separate business transactions. For the CJEU, the major point was that the copyright owner had received an appropriate remuneration with the first sale of the software program. Its intention to prioritize free trade may have induced the CJEU to gloss over some tricky doctrinal questions that the adoption of digital exhaustion raises.

15 Péter Mézei, “Theory of Functional equivalence”, 387-400.

16 Case C-263/18- Uitgeversverbond and Groep Algemene Uitgevers $v$ Tom Kabinet Internet BV and Others, Tom Kabinet was a Dutch company that runs an online marketplace for used e-books. The company bought e-books from individuals (who supposedly agree to the deletion of all copies and resells them to the public). 
Besides, the CJUE ruled that public must imply a certain scalability ${ }^{17}$ and access to new users, therefore not fulfilled.

If in the Usersoft the CJUE trailed the path towards a new functional approach of digital exhaustion detached from the traditional constricting dichotomy between tangible/intangible expressions, the Tom Kabinet case represents a significant backdrop from the path previously traded with a more narrow understanding of communication to the public.

Certainly, that e-books and computer software are different subjects and the Software Directive is not applicable since the CJUE rejected classifying e-books as products of software, although this decision is highly discussed among authors, whereby the different treatment between e-books and software come to exacerbate the discussion among scholars regarding the nature of e-books as combinations of hardware, software and content ${ }^{18}$ or as a simple electronic file ${ }^{19}$.

Nevertheless, we must outline that our understanding, of the core quest in both cases is the same and that the relevant subject was transferred via online download as for the sake of legal clarity and stability in light of the technological evolution. The digital exhaustion should apply to on demand distribution regardless of the means.

\section{b) Doctrinal Proposals}

Given the existing legal framework and the recent case law, the possible solutions conceived among scholars are quite divergent. That said, in a more conservative sector, no analogical solution is accepted in line with a restrictive interpretation that limits the first sale doctrine to cases where a copy has been transferred from seller to buyer. On the basis that recital 29 Info.Soc. Directive explicitly precludes the intangible copies of a work from the scope of exhaustion. Further, the CJUE ruled ${ }^{20}$ that in line with Article 3(1) of the

17 "public is present when several unrelated persons may have individual access to a work and this number is not to small considering the number of persons able to access to a work at the same time"

18 Eric Morgan, "Electronic Books and Related Technologies", Computer Libraries Review, Vol. 19 (10), (1999).

19 Donald T. Hawkins, "Electronic Books: A major publishing revolution. Part1: General Considerations and Issues", Vol. 24(4), (2000). 
InfoSoc., hyperlinking a publication does not constitute an act of communication to the general public, leading to numerous debates among authors regarding the meaning of communication and the place of exhaustion.

On the other side, congregating the majority of the doctrine, authors favour to the digital exhaustion, arguing that 'there is no difference between the sale of a tangible copy (such as CD) and the online transmission, though being carried out initially via online transmission, which also results in a tangible copy at the side of the recipient so that the rightholder's distribution right should have been in both cases exhausted ${ }^{21}$.

The proponents of a new conceptualization of the digital exhaustion are divided between by those who uphold as a solution the analogy to online transmission by outlining that the interests of the copyright holder are the same in online and offline transmissions and arguing that the recitals cited by the restrictive view only apply to the case of online service where a connection is constantly upheld. While others propose an analogy to the user's first copy $y^{22}$ as a middle ground approach that limits exhaustion to the first copy produced by the user after lawful download of the software arguing that the means of transmission in the digital world should not change impact the outcome.

Finally, the Theory of Functional Equivalence ${ }^{23}$ advocates that intangible downloads are functionally equivalent to physical sales, therefore implying that both are comparable so as to warrant applications of the principle of equal treatment. The theory's proponents argue that the sale of a computer program incorporated in a CD is the functional equivalent of a download, hence the network transmission is similar enough to the material delivered.

As we conceive it, one must account for the difficulties in the ever changing reality, and the fact is that a narrow interpretation of the legal framework cannot be bound with the practical challenges. As to whether the final solution relies exclusively upon a legislative amendment, we doubt it, since one must not forget that recognizing the digital exhaustion will have certain

21 Silke von Lewinski and Jörg Reinbothe, The WIPO Treaties on Copyright: A Commentary on the WCT, the WPPT, and the BTAP (2nd ed, Oxford University Press, 2015), 113.

22 Andreas Wiebe, "The Principle of Exhaustion”.

23 Péter Mézei, “The Theory of functional equivalence". 
negative side effects (such as boosting the second hand market, mass multiplication or the tendency to abusive behaviours). To this end, we strongly believe in the need for a broad and updated interpretation of the existing regulatory framework combined with technological tools in order to ensure the applicability of the exhaustion principle while safeguarding the critical interests and limiting risks.

\section{Technological Protection Measures: The regulation's Allied}

Rethinking the copyright normative infrastructure requires the necessary alignment with the new digitalized context while emphasising the centrality of the intangible subtract. Upon the generalized perception on the necessity of a legal intervention in order to preserve benefits and prevent unauthorized access and dissemination.

Considering the feasibility of a new set of extra-legal mechanisms via which it is possible to limit accessibility. This approach must be aligned with hard law policies, hence when synergically working together, both approaches affect the need for further legislative intervention ${ }^{24}$. According to Lessig's theory if, on one hand, we need hard law instruments in order to ensure property is protected, on the other, real-space code, such as online locks, is needed when laws and social norms are no longer enough.

Even so, digital tools have become a central element in the development of balanced solutions for the enforcement of intellectual property in the digital world. Given this, the Commission has outlined the need for more and more adaptive regulation on copyright in order to overcome fragmentation and frictions within a functioning single market ${ }^{25}$.

24 As suggested by Lessig, who outlines three possible extra legal mechanisms to bear in mind when considering the IP's particularities: (1) social norms (public beliefs); (2) the market (willingness to pay and the role of intermediaries) and (3) real space access restrictions-architecture (technological tools to limit access to the content, in Lawrence Lessig, Code: Version 2.0 (Basic Books, 2006).

25 Communication From The Commission To The European Parliament, The Council, The European Economic And Social Committee And The Committee Of The Regions: Towards A Modern, More European Copyright Framework, Available in: https://eur-lex.europa.eu/legal-content/ $\mathrm{EN} / \mathrm{TXT} /$ ?uri=COM\%3A2015\%3A626\%3AFIN 
After the regulatory setback regarding the digital exhaustion with the digital Single Market Directive, we outline the need for considering the development of tools in collaboration efforts between different actors. For that end, we underline two technologies that can play a major role in combating the negative side effects of online challenges and ensuring the feasibility of the digital exhaustion:

a) Forward and Delete System ${ }^{26}$, also suggested in the UsedSoft and in line with the provision on Article 5(1) Software Directive. By ensuring the protection of the digital content and by avoiding an excessive number of existing unnecessary copies of the same work. The technical implementation of a forward and delete system will certify future acquisitions that, even if the work is resold, all the temporary copies are destroyed in each transmission.

b) Jockchain solution ${ }^{27}$, in the digitally connected environment, it has become more difficult for rights owners to assert their ownership and to prove the authenticity and novelty of copyrightable works without a central registration. The blockchain can be useful as a public record for copyright. It can also be particularly important for our case in securing online transmissions of protected content (such as e-books).

Since the main characteristics of blockchain are the high security, the immutability (data contained in the blockchain cannot be erased), transparency and availability, unlike any regular database, the blockchain allows anyone to see who owns the book and the blockchain addresses cannot be edited ${ }^{28}$.

In sum, the Blockchain technology enables real time tracking of e-books, including the tracking of illegal uses of the copies while guaranteeing that the previous owner will totally lose control over the e-book after resale. Thus, the

26 João Marecos, “O Esgotamento do Direito de Distribuição sobre Obras Digitais", Revista de Direito Intelectual, Vol 1, 2014, 59-87.

27 Blockchain is an open ledger information too, used to record and track transactions. This information is shared in peer to peer network so that all parties can see, exchange, and verify it. Due to these characteristics, blockchain can be a useful tool for IP protection as it could also show evidence of registered and unregistered rights.

28 Google has recently started the first initiative to implement the blockchain technology for e-books. The idea of the project is to create a place (platform) to display digital books Editions At Play decided to apply blockchain technology to e-books in order to allow them to be owned as physical books due to the ability to track this transaction. For more information www.pocket-lint. com/phones/news/google/136670- google-editions-at-play-explained-what-are-books-that-can-tbe-printed (accessed 21 December 2020). 
immutability and transparency characteristics of the blockchain also favour the application of digital exhaustion. Ultimately, we strongly consider that the synergy between hard law and technical applications can truly have a positive impact not only in copyright, in general, but particularly in the applicability of the digital exhaustion.

\section{Conclusion}

That being said, the EU copyright doctrine must evolve and adapt to the new level of digital dissemination while congregating a set of unprecedented efforts to modernize the EU Digital Single Market without falling behind in practical challenges.

The principle of exhaustion is of paramount importance for both endorsing the functioning of the internal market and preserving copyright protection while guaranteeing the subject's economic interests. In fact, denying the digital exhaustion could deprive courts of a prevailing instrument for balancing the divergent objectives in copyright protection. Besides, as the Usersoft has demonstrated that admitting the principle of exhaustion did not destroy the market or severely affected the software industry. Actually, it might even encourage further developments.

Future additional clarification on this matter is certainly needed thus exhaustion has not been applied to the distribution of e-books because of uncertainties in the legislation and concerns from copyright holders. Undoubtedly, integrating the digital exhaustion would be majorly beneficial for rightsholders by providing certainty and more fair and competitive prices.

Furthermore, the existing regulation must be counterweighted with interests and potential risks, therefore allowing space to ensure a successful ecosystem to enable experimentation and learning by avoiding over-and-under inclusiveness issues. We strongly believe that the existing legal framework must be revised and adapted in order to properly protect rightsholders without restricting the lawful use of copyrightable works, along with a combined use of technologies to proactively enforce the Law. 